\title{
ESSAS COISAS NÃO LHES PERTENCEM: RELAÇÕES ENTRE LEGISLAÇÃO ARQUEOLÓGICA, CULTURA MATERIAL E COMUNIDADES
}

These Things do not Belong to You: Relationships between Archaeological Legislation, Material Culture, and Communities

Lúcio Menezes Ferreira ${ }^{1}$

\section{RESUMO}

A conferência trata das relações entre legislação arqueológica, cultura material e comunidades. Apresenta-se, inicialmente, um esboço histórico das legislações sobre patrimônio cultural no Ocidente e seus usos contemporâneos; em seguida, mostra como práticas arqueológicas alternativas, a exemplo da arqueologia comunitária, lidam com esse problema. Argumenta-se que essa discussão é bastante pertinente ao momento atual, especialmente o brasileiro, assoberbado pela arqueologia de contrato. Traz-se essa questão à baila na última parte da conferência, a modo de conclusão.

Palavras-chave: Legislação arqueológica, comunidades, cultura material.

\begin{abstract}
The conference deals with the relationship between archaeological legislations, material culture, and communities. In first place it presents a historical sketch of the heritage legislation in the West and its contemporary uses. Second, it shows how alternative archaeological practices, such as the archeology community, deal with these problems. This whole discussion is quite relevant currently, especially in Brazil, overwhelmed by contract archeology. It rises up this issue in the latter part of the conference.
\end{abstract}

Keywords: Archaeological legislation, communities, material culture.

\section{RESUMEN}

La conferencia analiza las relaciones entre legislación arqueológica, cultura material y comunidades. Presenta inicialmente un dibujo histórico de las legislaciones sobre patrimonio cultural en el Occidente y sus usos contemporáneos. A continuación, discute como practicas arqueológicas alternativas, como la arqueología comunitaria, examina esto problema. Esta discusión general, que será hecha en la última parte de la conferencia, es muy relevante actualmente, especialmente en Brasil, que se encuentra abrumado por la arqueología de contrato.

Palabras clave: legislación arqueológica, comunidades, cultura material.

\footnotetext{
${ }^{1}$ Laboratório Multidisciplinar de Investigação Arqueológica/UFPel; CNPq
} 
"O que une os indivíduos não é cimento" (Norbert Elias. A Sociedade dos Indivíduos, 1939)

O tema dessa mesa redonda - cultura material e comunidades - permite múltiplas abordagens, a partir de áreas disciplinares as mais diversas. Seria impossível condensá-las numa única conferência. Porém, uma das questões centrais, pontuada, sob diferentes matizes, no livro organizado pelo antropólogo Arjun Appadurai (1988), refere-se a como as coisas têm vida social e entranham-se nas cosmologias das comunidades. Os estudos sobre a materialidade discutem, ainda, os modos pelos quais as coisas e as sociedades se co-produzem e como a cultura material serviu e serve como lastro para o governo, nacional ou colonial, das comunidades (BUCHLI, 2007; GOSDEN, 2004; THOMAS, 1991; GIVEN, 2004). Outra influente abordagem é a do sociólogo Bruno Latour. Rompendo o dualismo sujeito-objeto, ele incentiva uma interpretação simétrica entre humanos e não humanos e enfatiza a ação social das coisas sobre ambos (LATOUR, 2008). Em suma, nos últimos anos, descobrimos que a cultura material é animada. É viva e pulsante. As coisas têm anima; são estruturantes e influem nossos comportamentos (GOSDEN, 2005). Elas circunscrevem memórias sociais, fixam calendários, inspiram celebrações (JONES, 2007). Comunidades e coisas se emaranham (HODDER, 2012).

Contudo, há uma classe de coisas que não pertence plenamente às comunidades. Continuam exercendo ação social sobre elas, mas não lhes pertencem inteiramente. Melhor dizendo: a rigor, sim, as coisas estão ali e as comunidades lhes conferem uso. Mas reina sobre elas uma ambivalência fundamental. As coisas estão no local. Todos as vêem. As comunidades podem tocá-las. Podem significá-las, associá-las afetivamente à memória da ancestralidade, torná-las marcos do direito à posse da terra e, portanto, da luta pela cidadania. No entanto, mesmo estando no local, essa classe de coisas gravita no global, na categoria difusa do universal, do pertencente à Nação ou a toda a humanidade.

Refiro-me à classe das coisas arqueológicas. Pesam sobre elas sanções legislativas variadas, desde os níveis municipais, até os nacionais e internacionais. Normalmente, coisas arqueológicas e comunidades são enfeixadas pela retórica pedagógica dos nacionalismos, disseminando-se pervasivamente a Nação para cada um de seus membros (DissemiNation, conforme o criativo neologismo de Homi Bhabha 1990). Ambas são atadas pela liga pegajosa da "comunidade imaginada" (ANDERSEN, 1983): nenhum indivíduo de uma nação, por menor que ela seja, conhece todas as coisas arqueológicas com as quais se compôs sua 
identidade nacional; e tampouco saberá ou sequer ouvirá falar dos outros membros de sua nação.

As legislações arqueológicas têm o poder de arregimentar as coisas que definem identidades nacionais, a despeito, quase sempre, dos desejos e deliberações das comunidades locais. Aquele sítio e todas as suas coisas estão ali, na comunidade; ela pode pisá-lo, manipular as coisas que formam o "registro arqueológico"; pode usá-lo como fonte de recurso alimentício ou materialização do sagrado (FOURMILE, 1989). Porém, a legislação, ao lado de arqueólogos e arqueólogas, podem auferir-lhes valor nacional ou universal. E, por mais que arqueólogos e arqueólogas possam consultar as comunidades e considerar-lhes as demandas, a legislação, como expressão de poder da soberania de uma nação ou do estatuto do universal, diz às comunidades que, com efeito, aquelas coisas estão ali, mas é como se não estivessem. Não são, a rigor, de ninguém, mas de todos que vivem numa nação ou de toda a humanidade; elas pertencem a todos "nós", mesmo àqueles que nunca as viram e jamais as verão.

Os estudos contemporâneos sobre cultura material, com seus enunciados sobre a vida social e estruturante das coisas, raramente se detém sobre essa ambivalência fundamental das legislações arqueológicas. É comum que os mesmos falem das coisas como semióforos; dissertem sobre suas ressemantizações, mapeando os cambiantes significados que elas adquirem em seus deslocamentos por diferentes contextos institucionais, culturais e políticos. Descreve-se a longa biografia das coisas: seu renascimento durante as escavações (até então as coisas estavam enterradas e mortas), sua trajetória nos laboratórios, sua filiação a um táxon e disposição numa coleção, até seu posterior aprisionamento nas vitrines dos museus.

Entretanto, o primeiro aprisionamento das coisas é decretado pelas legislações arqueológicas. Elas se assenhoram das coisas, modelando-as na fôrma das categorias nacional e universal. É verdade, também, que as comunidades pressionam legisladores, arqueólogos e gestores do patrimônio cultural para descentralizar o manejo, a salvaguarda e o uso da cultura material; pode-se indicar, nas últimas décadas, uma série de mudanças nas legislações patrimoniais e códigos de ética da pesquisa arqueológica graças à ação combativa de movimentos civis (SCHOFIELD e JOHNSON, 2006). Contudo, como argumentarei mais adiante, todas essas mudanças foram cooptadas em favor, principalmente, da comodificação da cultura material, da liberação das obras de engenharia e do turismo globalizado. A arqueologia de contrato, aqui, tem seu papel bem demarcado: ela é uma realidade de transação (FOUCAULT, 2008) entre as coisas e o mundo liberal, uma estratégia nos jogos de 
poder que permitem a neo-colonização das coisas pelo mercado. Ela possibilita que o mercado se justifique em linguagem patrimonial. Assim, hoje, as coisas arqueológicas são revestidas não apenas pelas tintas do nacionalismo ou pelas cores do estatuto do universal; elas são, também, fontes de legitimação do mercado.

Por essa razão, proponho à discussão, nessa mesa redonda, o tema das relações entre legislação arqueológica, cultura material e comunidades. Inicialmente, farei um esboço histórico das legislações sobre patrimônio cultural no Ocidente e demarcarei seus efeitos contemporâneos; em seguida, delinearei como práticas arqueológicas alternativas, a exemplo da arqueologia comunitária, lidam com esse problema. Toda essa discussão é bastante pertinente para o momento atual, especialmente o brasileiro, assoberbado pela arqueologia de contrato. Trarei essa questão à baila na última parte conferência, a modo de conclusão.

\section{As Coisas nas Malhas da Legislação Arqueológica}

As relações entre as coisas e as legislações arqueológicas, no Ocidente, têm uma longa história de genealogias e apropriações articuladas ao processo de formação da ideia de patrimônio cultural. Quando emergiu na modernidade, o patrimônio cultural foi, sobretudo, criação das instituições jurídicas do Estado. Para parafrasear o antropólogo Victor Turner (2005), o patrimônio cultural surgiu como momento de passagem: ao desintegrar as comunidades tradicionais, o Estado moderno inventou o patrimônio cultural, proscrevendo ou assenhorando-se de símbolos antigos. Os métodos sangrentos de criação dos Estados modernos, a partir do Renascimento, acompanharam-se da definição do bom gosto, da eleição dos estilos transmissíveis: o reconhecimento de um cânone de mestres e a delimitação de um corpus artístico a preservar-se. Instituíram-se, sobretudo nos nascentes Estados da península itálica, legislações de proteção e conservação do patrimônio. Uma das mais célebres é o decreto de 1601, por meio do qual o grão-duque Ferdinando de Médici listou dezoito pintores do passado cujas obras não se poderiam vender no exterior (GOMBRICH, 1992).

Iniciou-se assim, no Ocidente, o processo histórico que tornou o patrimônio como categoria de pensamento e ação social. Ao eleger um cânone, concebia-se uma maneira de compreender o mundo e de nele atuar. Daí a mescla entre Estado e cânone, entre as formas jurídicas de governabilidade e a arte. Pensava-se e constituía-se o Estado não só pela força do Direito e da conquista, mas, também, como obra de arte, resultado da criação consciente embasada em manifestos e técnicas (BURCKHARDT, 2012). Assim, o vocabulário político 
da modernidade codificou-se, desde o seu nascimento, em prescrições sobre os usos do passado (SKINNER, 1996). Passou-se a selecionar e institucionalizar a herança que os mortos legaram aos vivos (uma das manifestações filosóficas disso é o espanto de Comte com a superpopulação dos cemitérios!).

As sociedades do presente dispuseram as regras legais do culto ao passado. $\mathrm{O}$ estudo do passado, inicialmente por meio da filologia, da arqueologia e da história (e isso, pelo menos, desde Vico), torna-se princípio epistemológico, índice da organização política do presente e brasa da imaginação utópica, das projeções futuras da sociedade (HORKHEIMER, 1970). Essa "virada epistemológica" radicalizou-se no século XVIII, o "século das revoluções": a atualidade é interrogada filtrando-se o passado, selecionando-se porções dele para circunscrever-se a singularidade de uma trajetória histórica, um "nós" que remeteria a uma configuração cultural singular (FOUCAULT, 1996).

Deu-se azo à noção de cidadania como inextricavelmente atada à história, às coisas, ao território e à língua. Explico-me: desde o século XVIII, num processo que só fez acentuarse progressivamente a partir do século XIX, o indivíduo, o cidadão do mundo liberal, é impensável fora da rede social que o liga às tradições nacionais declinadas pelo Estado (ELIAS, 1994). Daí a proliferação de leis que asseguram destino específico às coisas arqueológicas: elas são restauradas, preservadas, exibidas nos museus e nas praças públicas. A legislação patrimonial - como de praxe na constituição histórica moderna da jurisprudência - apóia-se, para tanto, num conjunto de expertises e ciências: convocam-se museólogos, antropólogos, arqueólogos, historiadores, conservadores e arquitetos para assinar o veredicto patrimonial.

Nada disso nos é estranho. Em nossas sociedades, as práticas judiciárias, articulandose a várias ciências, instituíram o inquérito e o exame como forma de chegar-se à verdade e fundar uma técnica de gestão, uma modalidade de administração estatal da economia e da política (FOUCAULT, 2002). O que chamamos de patrimônio cultural não escapou a esses procedimentos do exame e do inquérito: as ciências, tradicionalmente, foram chamadas para fundar uma razão jurídica sobre o passado, administrar o legado cultural e dizer aos indivíduos quais são, e quais não são, suas filiações identitárias. Em nossas sociedades há, ainda hoje, um estatuto jurídico das identidades sociais, para cujo funcionamento ativa-se a patrimonialização das coisas. Para dizê-lo com um trocadilho: desde o século XVIII, nenhum governo governa sem patrimônio cultural (FERREIRA, 2009a). 
Assim é que, passadas mais de uma década do século XXI, dispomos de uma pletora legislativa regulando as coisas arqueológicas. Internamente, no Brasil, temos os Planos Diretores ligados às Secretarias de Cultura dos municípios; temos ainda, em nível federal, as resoluções do IPHAN, particularmente a Portaria $n^{\circ} .230$ (de 17 de dezembro de 2002), que normatiza as fases de obtenção de licença ambiental para as obras de engenharia que impactem ou destruam o patrimônio arqueológico; finalmente, na esfera transnacional, temos a atuação, dentre outros organismos, da UNESCO e, também, as várias Cartas Internacionais, emanadas de Convenções a partir das quais são publicados documentos que norteiam os procedimentos técnicos e éticos para a pesquisa, conservação e proteção das coisas arqueológicas.

Eis, assim, que as coisas arqueológicas estão cercadas pela retórica legislativa da preservação. Mas quais são, propriamente, os tropos que povoam essa imaginação legislativa? Tomemos o exemplo da UNESCO. A linguagem patrimonial da instituição, não obstante a incorporação da noção de diversidade cultural, francamente reforça valores predominantemente ocidentais. Isso se clarifica no endosso da ideia de herança cultural mundial e universal: ela invasivamente reconfigura projetos coloniais, ao mapear territórios margeados por fronteiras nacionais (MESKELL, 2002). É inegável, contudo, que muitas comunidades, fortalecendo-se em movimentos civis, impulsionaram a reformulação das legislações arqueológicas. É o caso, por exemplo, dos aborígenes australianos e dos indígenas norte-americanos, os quais, junto a arqueólogos e arqueólogas engajados, garantiram o direito de gestão de seu próprio patrimônio e de repatriação arqueológica (SIMPSON, 2001; COLLEY, 2002; FERREIRA, 2009a). Acrescente-se, ainda, que sem os movimentos civis não haveria crítica ao cânone ocidental e ao logocentrismo da retórica patrimonial, as legislações arqueológicas e os códigos de ética de pesquisa permaneceriam estacionados e várias disciplinas, como a arqueologia da escravidão, não emergiriam (FERREIRA, 2009b).

Contudo, pergunto-me se, a esta altura dos acontecimentos mundiais, essas legislações e códigos de ética não estão sendo constantemente capturadas pelo mercado e pelas práticas nacionalistas. Coisas e monumentos, em vários quadrantes do mundo, vêm sendo prodigamente enlaçadas nas malhas dos "novos" e "velhos" nacionalismos, tanto no Leste Europeu, como no Oriente Médio, Japão e China (KOHL et al, 2007). Mesmo o discurso do multiculturalismo é, nesse processo, apetecedor, especialmente na América Latina. Ainda que as diversas legislações arqueológicas, modelos de gestão do patrimônio e, inclusive, as constituições modernas, incorporem o conceito de multiculturalismo, fazem-no 
para homogeneizar as diferenças e impedi-las de dialogar; evocam-no para recriar narrativas nacionalistas e colonialistas (GUTHRIE, 2010; ARMSTRONG-FUMERO, 2009; GNECCO, 2009). É que nossas sociedades, mesmo admitindo e celebrando suas culturas plurais, não dispensaram a "tirania burocrática", com seu correlato princípio da autoridade centralizada na Lei para gerir os indivíduos e suas identidades (CERTEAU, 1993).

Ao enredarem as coisas, as legislações arqueológicas e seu recente apelo multicultural parecem confeccionar "mordaças sonoras" (SARTRE, 1979) para os grupos subalternos. As legislações arqueológicas têm sido hábeis para atuar como aparelhos de captura (DELEUZE e GUATTARI, 1980), absorvendo a fala dos grupos subalternos no intuito de burocratizá-las e dar-lhes pretensa entonação democrática. Elas declinam os verbos da partilha das coisas, de sua gestão comunitária, mas somente para melhor agenciá-las e represar a diversidade cultural que elas comportam. Onde essas artimanhas são mais visíveis? Exatamente na exegese dos juristas ingleses do patrimônio, aqueles que, na linha de John Henry Merryman (2000), John Carman (2005) e Derek Gillman (2010), tratam o patrimônio arqueológico como herança de toda a humanidade, como recurso cultural a ser administrado em fóruns internacionais e explorado como dividendo turístico. Esvaziam, assim, a pluralidade de representações que as comunidades conferem às coisas, amalgamando-as. É notório que essa vertente jurídica de análise se enfeixa aos interesses do mercado turístico. $\mathrm{O}$ que interessa ao turismo nacional e internacional que alimenta cartões de crédito, redes de hotéis e companhias aéreas, é, obviamente, o consumo. E o pretexto do consumo é a fruição do chamado patrimônio universal.

Ora, a relação entre turismo e arqueologia surgiu ao largo dos séculos XIX e XX, junto com a industrialização, o colonialismo e a construção de identidades nacionais (CHAMBERS, 2000). Porém, desde o final do século XX, a importância do turismo arqueológico (não só o arqueológico, obviamente) aumentou consideravelmente como indústria global, tornando-se justificativa para o desenvolvimento econômico em todo o mundo. Reitera, nesse processo, o que já fazia no século XIX: o uso e abuso das coisas arqueológicas para estruturar identidades nacionais e, agora, neocoloniais. Introduziu, entretanto, uma inovação: a participação das comunidades locais nas escavações arqueológicas e na gestão do patrimônio (BARAM, 2007). A comodificação das coisas arqueológicas para o turismo, além de reinscrever as identidades nacionais nos novos registros proporcionados pelas viagens internacionais, acomoda confortavelmente as interpretações e cosmologias das comunidades. Como Silberman (2002) mostra para o caso 
do Peru, a participação das comunidades, invocadas sob o signo da multivocalidade e do multiculturalismo, assegura a autenticidade da indústria turística.

Em nosso contexto mais imediato, a América do Sul, as coisas arqueológicas, como espetáculos do turismo global, se conjugam com os processos de expropriação de terras em favor de hotéis multinacionais e redes de serviço (BELLI e SLAVUTSKY, 2010; RIVOLTA et al, 2010). Às comunidades restam, quase sempre, as sobras da economia turística: a venda de artesanatos e empregos subalternos, mas nunca a gestão comunitária dos negócios e, tampouco, a condução efetiva dos chamados projetos de desenvolvimento auto-sustentável. Reconfiguram-se, desse modo, as heranças do colonialismo no que elas têm de mais notável: a apropriação das histórias nativas e a expropriação de terras.

O turismo arqueológico instila, ainda, um paradoxo. O turista mergulha na ambivalência das políticas de representação e gestão do patrimônio cultural. De um lado, ele é submetido às retóricas locais do patrimônio arqueológico, com suas noções de identidade regional e nacional. Submetem-no, portanto, ao patrimônio como lugar, isto é, à identidade enquanto sinônimo de território compartido, ainda que, para o gosto do turista, tal identidade possa ter talhe exótico (e, para as indústrias turísticas, tanto melhor que ela o tenha). De outro, seguindo-se os enunciados do antropólogo Marc Augé (2007), o turismo arqueológico, com sua retórica do universal, da identidade partilhada pelas realizações culturais de toda a humanidade, é acionado como não-lugar. Como nos supermercados, rodovias, shoppings e aeroportos, o turismo arqueológico intenta uniformizar práticas culturais. O turista é apresentado ao Mesmo, ao reconhecível, e o turismo arqueológico é encenado como espetáculo de consumo frugal do mundo globalizado.

\section{Contornando o Problema}

Assim é que as coisas arqueológicas são colhidas pelas malhas das práticas nacionalistas e do turismo global. Esse processo incrementou-se a partir dos anos 1990, com o avanço do neoliberalismo e o recrudescimento das guerras em escala global. Não por acaso, já no final dos anos 1990, uma obra apontava que a arqueologia estava sob fogo (MESKELL, 1998). Contudo, o uso das coisas arqueológicas como alegoria nacionalista e comodificação vem sendo combatido pelas comunidades locais. Cada vez mais, nas sociedades contemporâneas, as comunidades se engajam num movimento de descolonização da arqueologia em seus territórios (SMITH e WOBST, 2005). Assim, nas últimas duas décadas, 
emergiram campos disciplinares que remodelaram o trabalho arqueológico junto às comunidades. Grosso modo, no-los conceituam como arqueologia pública (MERRIMAN, 2004), arqueologia colaborativa (COLWELL-CHANTHAPHONH e FERGUSON, 2008; MACDAVID, 2004) e arqueologia comunitária (MARSHALL, 2002; TULLY, 2007). Nas camadas que os constituem, lançam-se nesses campos as sementes da democratização do conhecimento arqueológico (SHACKEL, 2001; HOLTORF, 2006); perspectivam suas paisagens como uma "arqueologia vista de baixo" ("archaeology from below") (FAULKNER, 2000); descrevem-nos, ainda, como novas teorizações sobre as relações entre o presente e o passado, a pesquisa arqueológica e o público (SIMPSON e WILLIAM, 2008).

Não há, propriamente, uma ontologia que coalesça as propriedades desses campos. Pode-se falar, porém, de dois elementos metodológicos comuns, muito presentes na literatura. O primeiro é a etnografia arqueológica. Grosso modo, são três os objetivos da etnografia arqueológica: entender as cosmologias e representações das comunidades sobre as coisas arqueológicas e suas narrativas sobre o passado; analisar as políticas de negociação de identidades e os conflitos que caracterizam as comunidades; promover um espaço intercultural, de diálogo permanente entre a equipe de arqueologia e a comunidade, abrindo-se oportunidades para a educação mútua e comparações entre os discursos arqueológicos e locais (HAMILAKIS e ANAGNOSTOPOULOS, 2009).

Não se trata, portanto, de educação patrimonial, ao modo como ela vem sendo majoritariamente feita no Brasil (FERREIRA, 2010a; FERREIRA e SANCHES, 2011). Na etnografia arqueológica, o primeiro a educar-se é o arqueólogo. Procura-se, pois, contrabalançar o desnível de poder entre a arqueologia e as comunidades. Não é o arqueólogo que educa, unilateralmente, a comunidade, mas, sim, é ele quem aprende com ela: no trabalho etnográfico, ele dialoga sobre os anseios identitários da comunidade; descobre (descobrir na dupla acepção de inventariar e inventar) a pluralidade de significados que as comunidades atribuem aos artefatos e sítios arqueológicos. A etnografia arqueológica, assim, tem fundamento simultaneamente político e epistemológico. Ela provoca a pensar a diversidade cultural como relação indestrinçável entre o presente e o passado e, ainda, sobre as tecnologias de governo promovidas pela ativação do patrimônio cultural.

O segundo elemento metodológico comum nesses campos arqueológicos é a integração das comunidades em todas as etapas da pesquisa arqueológica: desde a formulação do projeto de pesquisa, elaborado em consonância com as demandas das comunidades, até a prospecção, sondagem, escavação de sítios arqueológicos, curadoria e análise da cultura 
material em laboratório. Trata-se de instrumentalizar as comunidades para manejar seu patrimônio arqueológico. As políticas de representação do patrimônio arqueológico, suas formas de extroversão, exploração e administração são, também, decididas conjuntamente entre as comunidades e os arqueólogos. As comunidades, nessa linha, não são mais "informantes", guias locais para a procura de sítios ou "peões" nas escavações. A tentativa é nivelar as relações de poder entre arqueólogos e comunidades e descentralizar a autoridade da instituição arqueológica.

O arqueólogo torna-se colaborador da comunidade. Ele tenta esmaecer, nesse quadro metodológico, sua imagem tradicional: o estrangeiro, aliado da administração colonial ou do Estado nacional, que se apropria das coisas arqueológicas locais e define, em via de mão única, a "diversidade cultural da humanidade". Ao contrário: aqui, como em qualquer reflexão antropológica, a cosmologia do arqueólogo contrasta-se com a cosmologia da comunidade; o arqueólogo, nesse contraponto, não apenas se reinventa culturalmente; descobre, no mesmo passo, a pluralidade de significados que repousa sobre os artefatos, os monumentos e a paisagem.

\section{De Volta às Malhas}

Esses campos arqueológicos, portanto, visam à gestão e interpretação partilhada das coisas arqueológicas e a promover a diversidade cultural. Mas, talvez, hoje eles estejam, na maioria dos casos, apenas contornando o problema. Como já apontei, as legislações arqueológicas continuam a prender as coisas em suas malhas e salvaguardando o nacionalismo e o turismo global (APPADURAI, 2002). Ao dizê-lo, não estou afirmando que o trabalho arqueológico com as comunidades, bem como a ativação das diversas legislações arqueológicas, é parte de um plano maquiavélico, sobre o qual existe um acordo consensual por parte de elites, governos e mercado turístico global. Tampouco estou argumentando que arqueólogos e arqueólogas são agentes acríticos e ingênuos ante a comodificação, nacionalização e colonização das coisas arqueológicas. Finalmente, não estou minorando a atuação incisiva dos movimentos civis em prol de todas as mudanças que, pelo menos desde os anos 1960, efetuaram-se nas legislações arqueológicas, códigos de ética das pesquisas, instauração do ponto de vista nativo na história, descolonização metodológica da arqueologia e da antropologia, dentre outras cruciais e decisivas transformações. 
Porém, parece-me que há, hoje, uma acentuada tendência a que o trabalho arqueológico com as comunidades, ou a arqueologia pública (terminologia sob a qual se englobam, equivocadamente, diferentes disciplinas arqueológicas, como a arqueologia comunitária e a arqueologia colaborativa), não seja infenso ao nacionalismo, ao colonialismo e ao mercado. Mais uma vez, esclareço meu argumento de modo antitético. Sem dúvidas, a arqueologia pode trazer benefícios públicos (LITTLE, 2002). E, efetivamente, trata-se de uma "virada epistemológica" quando, como se fora no teatro de Augusto Boal, o público se torna poeta e protagonista da cena, e a mão-de-obra anônima que empunha os instrumentos de escavação não são apenas negras (SHEPERD, 2009). Para limitarmo-nos geograficamente, protagonizar as comunidades e viabilizar a institucionalização de projetos de arqueologia colaborativa, no Brasil, seria fundamental diante do atual contexto de luta das comunidades indígenas e quilombolas pela terra. Lamentavelmente, são poucos, entre nós, os trabalhos nessa linha (Cf. p. ex: SILVA, 2011; EREMITES DE OLIVEIRA E PEREIRA, 2012; BEZERRA, 2012; FUNARI e BEZERRA, 2012; FUNARI e CARVALHO, 2012), enquanto, em meio à Era do Plano de Aceleração do Crescimento (PAC), latifundiários, articulados ou não às bancadas do Congresso Nacional, se organizam (quando não agem violentamente) contra a demarcação de terras indígenas e quilombolas, conforme cotidianamente vemos em nossas cidades.

Mas, observam-se, no Brasil e alhures, as coisas arqueológicas, sob o beneplácito e ordenação da legislação patrimonial, legitimando os chamados planos de crescimento econômico ou projetos de desenvolvimento. A prática contemporânea que engendra tal legitimação é a arqueologia de contrato. Ela surgiu, historicamente, como realidade de transação entre as coisas arqueológicas e o liberalismo. E, hoje, a arqueologia de contrato vem fazendo um uso muito peculiar da arqueologia pública. Vale-se da disciplina, numa clara distorção de sua epistemologia e objetivos, como estratégia de marketing, como publicidade. Os projetos de desenvolvimento podem destruir os sítios, mas a arqueologia de contrato, aliada a essa versão sorrateira de arqueologia pública, diz-nos: “aqui estamos nós para preservar o passado para o futuro e educar a comunidade"! Eis que as empresas e governos, agora, conjugam destruição desenvolvimentista com preservação do passado. Quando não agem cinicamente, vendo a arqueologia como algo a tolerar-se (não se pode parar a obra devido a esses "caquinhos"!) ou pura e simplesmente como óbice ao andamento preciso do cronograma das obras. Mas a tônica majoritária, com raríssimas exceções, é ditada pela propaganda. 
Presumo que todos nós já vimos, no Brasil e no exterior, folhetos e prospectos de propaganda (quando não expressos em artigos e congressos científicos) apresentando a arqueologia de contrato como arqueologia pública. No Brasil, especialmente, ao que se nomeava como educação patrimonial costuma-se classificar, agora, como arqueologia pública, como se esta se limitasse à pedagogia patrimonial. Frisemos os códigos desse marketing acadêmico. Em primeiro lugar, nos manuais, cartilhas, folhetos e prospectos de "arqueologia pública" estampam-se os signos das empresas e instituições do governo que pagaram pelo trabalho arqueológico. É algo similar à propaganda das empresas "ecológicas" de cosméticos, como a Natura: exploremos prodigamente os recursos naturais, pois, afinal, "trabalhamos pela consciência da sustentabilidade e temos, hoje, vinte projetos para a melhoria da educação brasileira" (Cf. o sítio Natura Ekos e Instituto Natura). Os signos da propaganda ilustram, em segundo lugar, a empresa de arqueologia de contrato que ganhou a licitação para executar o trabalho. Vende-se o produto, muitas vezes, exibindo-se orgulhosamente fotos representando a "ciência em ação", onde os princípios metodológicos da arqueologia comunitária são artificialmente cenografados: mostra-se a comunidade trabalhando em todas as etapas da pesquisa arqueológica. Contudo, a verdade é que não se consulta previamente a comunidade para elaborar-se o "projeto de pesquisa", assim como não se delibera com ela acerca dos impactos econômicos e ambientais que as obras de engenharia ocasionarão. Em suma, segue-se tranquilamente a "melhor" tradição autocrática do Estado brasileiro: a imposição de projetos sem consulta à sociedade civil.

Legendas e textos das fotos falam em "despertar vocações arqueológicas e patrimoniais", em "garantia do direito à cultura e à memória" (como se as comunidades não tivessem cultura e memória!), em educação de jovens e adultos, em "empoderamento", em preparar os professores locais para os temas arqueológicos (quase sempre reduzidos à préhistória), em fomentar o artesanato local com motivos arqueológicos, e assim por diante. $\mathrm{O}$ que não se fala é que os membros da comunidade tornam-se os antigos "peões" dos trabalhos arqueológicos. Talvez numa escala ainda mais exploradora, uma vez que as comunidades, quase sempre, não são remuneradas, ou apenas lhes pagam, como se diz no Brasil, parcas "diárias". É quase o gift do contato: "dê-me suas coisas e paisagem, dou-lhe em troca educação, cultura arqueológica, ressignificação de sua memória e desenvolvimento". Aqui, a ironia do arqueólogo social latino-americano Felipe Bate sobre a arqueologia pública é perfeitamente cabível: ela pode ser entendida como um discurso "altamente progresista y democrático, sumado a un paternalismo conmovedor" (BATE, 1998:12). 
Como já disse Chris Gosden (2001), a arqueologia institucionalizou-se, na modernidade, como produto da filosofia liberal. Não nos libertamos inteiramente desse processo. Isso é evidente na própria aparição, nos Estados Unidos, da conjunção entre arqueologia de contrato e arqueologia pública. O termo arqueologia pública é cunhado, pela primeira vez, na obra homônima do Charles McGimsey (1972). O que impeliu MacGimsey a escrevê-la foi a legislação patrimonial que surgiu nos Estados Unidos dos anos 1960, designada como Cultural Resource Management (CRM). McGimsey estava preocupado, como tantos outros arqueólogos e arqueólogas, com a destruição acelerada de sítios arqueológicos conduzida pelos projetos capitalistas de desenvolvimento. Porém, nessa preocupação não repousa somente a boa consciência romântica da preservação, ou o chamado iluminista do público para a conservação dos "recursos culturais". Ao contrário. Rapidamente a CRM e a arqueologia pública puseram-se a serviço das empresas capitalistas e do governo, viabilizando obras de engenharia e os negócios turísticos. Aqui nasceu, bem nutrida e vigorosa, a arqueologia de contrato e sua aliança com a arqueologia pública.

Decerto que a arqueologia processual, que emergiu nesse mesmo contexto, se beneficiou grandemente com recursos para a pesquisa. Contudo, como recentemente argumentou Patty Jo Watson (2008), uma das lídimas representantes da arqueologia processual, mais de $90 \%$ da arqueologia praticada nos Estados Unidos, hoje, é feita por contrato, ligando-se à CRM e à arqueologia pública. Trigger (1984), em artigo clássico, já argumentava, em meados dos anos 1980, que o processualismo, com sua busca por regularidades transculturais e sujeição das culturas a sistemas, era expressão do imperialismo e nacionalismo dos Estados Unidos. O cerne da argumentação de Trigger é que a arqueologia se esteia em meio ao sistema mundial, na acepção de Immanuel Wallerstein. Equivale a dizer: durante a guerra fria, uma fração da arqueologia mundial institucionalizava-se na esfera do liberalismo.

Assim, esse vínculo contemporâneo entre arqueologia de contrato e "arqueologia pública" consubstancia-se no mercado, reproduzindo desigualdades sociais com retóricas patrimoniais. A questão não é apenas liberar as obras desenvolvimentistas, conquanto isso seja fundamental para o funcionamento do mercado. Trata-se, também, de acolher as comunidades, e todas as suas coisas arqueológicas, como peças publicitárias. Trata-se, ainda, de veicular a imagem de que a destruição também constrói. Destrói, mas preserva a pluralidade cultural. Devasta positivamente, inventariando paisagens, costumes e coisas nos 
arquivos, onde ulteriores consultas sobre a diversidade que nos caracteriza historicamente poderão ser feitas. Nesses arquivos, o passado estará registrado para benefício do futuro.

As coisas arqueológicas, assim, são comodificadas e atuam no mundo liberal. Elas enredam-se nas tramas do discurso liberal sobre a pluralidade cultural, o qual, depois de 1989, açambarca as diferenças e a diversidade em sua ideia de indivíduo e liberdade (Bauman 1998). Contudo, há mais. Os laços entre arqueologia de contrato e "arqueologia pública" remoçam velhos nacionalismos e colonialismos. Nesse ponto, permitam-me narrar uma experiência pessoal. Em maio do ano passado, tive a oportunidade de participar, como convidado, do congresso Archéologie de l'esclavage colonial, ocorrido no Musée du quai Branly, em Paris. O congresso foi organizado pelo Institut National de Recherches Archéologiques Préventives (INRAP), ligado ao Ministério da Cultura e Comunicação da França. Esse instituto é responsável pela arqueologia de contrato que se faz na França.

O INRAP, portanto, centraliza, via Estado, os trabalhos em arqueologia de contrato. Trata-se de uma forma de gestão e execução de arqueologia de contrato muito distinta do que se convencionou como o "modelo brasileiro" (Para outros exemplos, Cf. FERREIRA e SANCHES, 2011), mas afeito às práticas do "homem cordial" descrito por Sérgio Buarque de Holanda, isto é, propenso a não discernir e misturar as áreas de atuação do público e do privado. Pois bem, surpreendeu-me constatar, nos folhetos de propaganda do INRAP, três slogans correlatos. O primeiro: "nós escavamos sua história"; presumo que, de tão evidente, são dispensáveis maiores comentários sobre o tom nacionalista desse slogan. O segundo slogan relacionava-se à Guiana Francesa, cuja entonação era mais ou menos assim: “descobertas do passado francês na Guiana”. A modulação colonialista desse slogan é também bastante evidente, mas me atrevo a comentar que, quando tantos arqueólogos e arqueólogas se esmeram em refinar abordagens pós-coloniais e a descolonização da arqueologia, não deixa de ser espantoso ler sentença tão colonialista.

O terceiro slogan, por sua vez, é bastante recorrente na arqueologia de contrato que se faz mundo afora. Dizia algo do gênero: "o crescente número de sítios escavados pelo INRAP na França”. Acompanhava esse slogan dados quantitativos, representando-se, em mapas de distribuição, o número vertiginoso de sítios escavados pelo INRAP. Moral da história: antes da arqueologia de contrato, antes do INRAP, não conhecíamos esse número de sítios arqueológicos. Cabe-nos perguntar se dados numéricos sobre a quantidade crescente de sítios arqueológicos registrados e escavados resultam, verdadeiramente, em conhecimento. A meu ver, tal procedimento evidencia que a legislação arqueológica, ao agenciar as coisas, 
recoloca-as, via associação entre arqueologia de contrato e essa modalidade desvirtuada de arqueologia pública, nas malhas dos discursos nacionalistas e colonialistas, além de assegurar os interesses do mercado e as políticas liberais.

No Brasil, segundo os últimos dados, $98 \%$ das portarias emitidas pelo Instituto do Patrimônio Histórico e Artístico Nacional (IPHAN) são destinadas à arqueologia de contrato (ZANETTINI, 2009; WICHERS, 2010; TEGA, 2012). Na Argentina, bem como em outros países sul-americanos, a arqueologia de contrato já vai se posicionando firmemente no cenário acadêmico. A justificativa para essa inserção pervasiva, particularmente no Brasil, assemelha-se ao terceiro slogan do INRAP. No nosso caso, desatrelada, para o bem ou para o mal, de usos nacionalistas. Mas, nessa Era do PAC, a arqueologia de contrato, autenticandose agora como "arqueologia pública", agencia as coisas arqueológicas e recapitula o colonialismo interno acionado pela arqueologia brasileira dos séculos XIX e início do XX (FERREIRA, 2010b): aliena as histórias nativas e lidima a expropriação de terras.

Concluo lembrando o que disse David Lowenthal (2005) num debate com Henry Merryman: as leis patrimoniais raramente funcionam, pois a cultura material, além de estruturante, se vivifica conforme os contextos e as cosmologias das comunidades. É verdade. Porém, deve-se considerar, nas pesquisas que fazemos sobre a agência da cultura material, que as legislações arqueológicas aprisionam as coisas; e, hoje, são crescentemente alegorizadas como emblemas de bandeiras nacionalistas e colonialistas, atrações do turismo global e suportes do mercado liberal.

\section{Agradecimentos}

Aos amigos do LÂMINA (ICH/UFPel). Ao CNPq, pelo apoio. Aos amigos Aline Vieira de Carvalho e Pedro Paulo Funari, por me convidarem para integrar essa mesaredonda. A Márcia Bezerra, que partilhou comigo a mesa-redonda e com quem sempre aprendo muito. Aos alunos e alunas dos cursos de arqueologia no Brasil, nossa "comunidade imaginada". Não conheço pessoalmente a maioria deles. Mas escrevi essa conferência pensando neles, sem proselitismo paternal e evitando "educá-los para o patrimônio".

\section{Referências bibliográficas}

ANDERSEN, B. 1983. Imagined Communities: Reflections on the Origin and the Spread of Nationalism. London: Verso. 
APPADURAI, A. (ed.) 1988. The Social Life of Things: Commodities in Cultural Perspective. Cambridge: Cambridge U. P.

Archaeology, (1): 35-49.

2002. The Globalization of Archaeology and Heritage. Journal of Social

ARMSTRONG-FUMERO, A. 2009. A Heritage of Ambiguity: the Historical Substrate of Vernacular Multiculturalism in Yucatán, Mexico. American Ethnologist, (36): 2, 300-316.

AUGÉ, M. 2007. Não-Lugares: Uma Introdução à Antropologia da Sobremodernidade. Lisboa: 90 Graus Editora.

BARAM, U. 2007. Appropriating the Past: Heritage, Tourism, and Archaeology in Israel. In: KOHL, P; KOZELSKY, M; BEN-YEHUDA, N. (eds.). Selective Remembrances: Archaeology in the Construction, Commemoration, and Consecration of National Pasts. Chicago: The University of Chicago Press, pp. 229-325.

BATE, F. 1998. La Investigación en Arqueología. Critica: Barcelona.

BAUMAN, Z. Sobre o Comunitarismo e a Liberdade Humana, ou como Enquadrar o Círculo. In: O Mal-Estar da Pós-Modernidade. Rio de Janeiro: Jorge Zahar Editor, 1998, pp. 231-245.

BELLI, E; SLAVUTSKY, R. 2010. A Gestão Estatal do Patrimônio para o Desenvolvimento dos Setores Polulares da Quebrada de Humahuaka. In: FERREIRA, L. M; FERREIRA, M. L. M; ROTMAN, M. (orgs.). Patrimônio Cultural no Brasil e na Argentina: estudos de caso. São Paulo: CAPES/Annablume, pp. 145-159.

BEZERRA, M. 2012. Signifying Heritage In Amazon: A Public Archaeology Project At Vila De Joanes, Marajó Island, Brazil. Chungara, (44): 533-542.

BHABHA, H. K. 1990. Dissemination. In: BHABHA, H. K. (ed.). Nation and Narration. London: Routledge, pp. 291-322.

BUCHLI, T. 2007. Material Culture: Current Problems. In: MESKELL, L; PREUCEL, R. W. (eds.). A Companion to Social Archaeology. Oxford: Blackwell Publishing, pp. 179-194.

BURCKHARDT, J. 2012. O Estado como Obra de Arte. São Paulo: Penguin e Companhia das Letras

CARMAN, J. 2005. Against Cultural Property: Archaeology, Heritage and Ownership. London: Duckworth.

CERTEAU, M. 1993. La Culture au Pluriel. Paris: Éditions du Seuil.

CHAMBERS, E. 2000. Native Tours: The Anthropology of Tourism and Travel. Prospect Heights, III: Waveland Press.

COLLEY, S. 2002. Uncovering Australia: Archaeology, Indigenous People and the Public. Sidney: Allen and Unwin. 
COLWELL-CHANTHAPHONH, C.; FERGUSON, T.J. (ed.). 2008. Collaboration in Archaeological Practice: engaging descendent communities. Lanham: Altamira Press.

DELEUZE, G; GUATTARI, F. 1980. Mille Plateaux: Capitalisme et Schizophrénie. Paris: Éditions de Minuit.

ELIAS, N. 1994. A Sociedade dos Indivíduos. Rio de Janeiro: Jorge Zahar Editor.

EREMITES DE OLIVEIRA, J; PEREIRA, L. M. 2012. Terra Indígena Buriti: perícia antropológica, arqueológica e histórica sobre uma terra terena na serra de Macaraju, Mato Grosso do Sul. Dourados: UFGD.

FAULKNER, N. 2000. Archaeology from Below. Public Archaeology, (1): 1, 21-33.

FERREIRA, L. M. 2009a. Patrimônio Arqueológico, Pós-Colonialismo e Leis de Repatriação. In: FUNARI, P. P; PELEGRINI, S; RAMBELLI, G. (orgs.). Patrimônio Cultural e Ambiental: questões legais e conceituais. São Paulo: Annablume, p.77-96.

2009b. Arqueologia da Escravidão e Arqueologia Pública: Algumas Interfaces. Vestígios: Revista Latino-Americana de Arqueologia Histórica, (3): 1, 9-23.

. 2010a. Arqueología Comunitaria, Arqueología de Contrato y Educación Patrimonial en Brasil. Jangwa Pana: Revista del Programa de Antropología de la Universidad del Magdalena, (9): 95-102.

. 2010b. Território Primitivo: a institucionalização da arqueologia no Brasil (1870-1917). Porto Alegre: Editora da PUCRS.

FERREIRA, L. M; SANCHES, P. L. M. 2011. Arqueologia de Contrato e Educação Patrimonial no Brasil: algumas provocações. In: FERREIRA, L. M; FERREIRA, M. L. M; ROTMAN, M. (orgs.). Patrimônio Cultural no Brasil e na Argentina: estudos de caso. São Paulo: CAPES/Annablume, pp. 161-172.

FOUCAULT, M. 1996. ¿Qué es la Ilustración? Madrid: Las Ediciones de La Piqueta. . 2002. A Verdade e as Formas Jurídicas. Rio de Janeiro: NAU Editora/PUC. . 2008. Nascimento da Biopolítica. São Paulo: Martins Fontes.

FOURMILE, H. 1989. Who owns the past? Aborigines as captives of the archives. Aboriginal History, (13): 1, 1-8.

FUNARI, P. P; BEZERRA, M. 2012. Public Archaeology in Latin America. In: SKEATES, R; MACDAVID, C; CARMAN, J. (eds). The Oxford Handbook of Public Archaeology. Oxford: Oxford University Press, V I, pp. 100-115.

FUNARI, P. P; CARVALHO, A. V. 2012. Inclusion in Public Archeology in Brazil: Remarks on Collaborative Practices. Archaeologies (8): 5-25.

GILLMAN, D. 2010. The Idea of Cultural Heritage. Cambridge: Cambridge U. P. 
GIVEN, M. 2004. The Archaeology of Colonized. London: Routledge.

GNECCO, C. 2009. Caminos de la Arqueología: de la Violencia Epistémica a la Relacionalidad. In: FERREIRA, L. M. (org.). Arqueologia Amazônica: História e Identidades. Boletim do Museu Paraense Emílio Goeldi-Ciências Humanas, (4): 1, 15-26.

GOMBRICH, E. H. 1992. Réflexions sur l'histoire de l'arte. Nímes: Jacqueline Chambon.

GOSDEN, C. 2001. Postcolonial Archaeology: Issues of Culture, Identity, and Knowledge. In: HODDER, I. (ed.). Archaeological Theory Today. Cambridge: Polity Press, pp. 241-261.

2004. Archaeology and Colonialism: Cultural Contact from 5000 BC to the Present. Cambridge: Cambridge U. P.

(12): 3, 93-211.

2005. What do Objects Want? Journal of Archaeological Method and Theory,

GUTHRIE, T. H. 2010. Dealing with Difference: Heritage, Commensurability and Public Formation in Northern New Mexico. International Journal of Heritage Studies, (16): 4-5, 305-321.

HAMILAKIS, Y; ANAGNOSTOPOULOS, A. 2009. Public archaeology: archaeological ethnographies. Public Archaeology, (8): 2-3, 65-87.

HODDER, I. 2012. Entangled: An Archaeology of the Relationships between Humans and Things. Oxford: Wiley-Blackwell, 2012.

HOLTORF, Cornelius. 2006. Can less be more? Heritage in the Age of Terrorism. Public Archaeology, (5): 2, 101-110.

HORKHEIMER, M. 1970. Origens da Filosofia Burguesa da História. Lisboa: Editorial Presença.

HUME, I. N. The Why, What, and Who of Historical Archaeology. In: Historical Archaeology: A Comprehensive Guide for Both Amateurs and Professionals to the Techniques and Methods of Excavating Historical Sites. New York: Alfred Knopf, 1969, pp. 7-20.

JONES, A. 2007. Memory and Material Culture. Cambridge: Cambridge U. P.

KOHL, P; KOZELSKY, M; BEN-YEHUDA, N. 2007. Introduction: Selective Remembrances: Archaeology in the Construction, Commemoration, and Consecration of National Pasts. In: KOHL, P; KOZELSKY, M; BEN-YEHUDA, N. (eds.) Selective Remembrances: Archaeology in the Construction, Commemoration, and Consecration of National Pasts. Chicago: The University of Chicago Press, pp. 1-28.

LATOUR, B. 2008. Reensamblar lo Social: una introducción a la teoría del actor-red. Buenos Aires: Manantial. 
LITTLE, B. (ed). 2002. Public Benefits of Archaeology. Florida: University Press of Florida.

LOWENTHAL, D. 2005. Why Sanctions Seldom Work: Reflections on Cultural Property Nationalism. International Journal of Cultural Property, (12): 393-423.

MARSHALL, Y. 2002. What is Community Archaeology? World Archaeology, (32): 2, 211 219.

MCDAVID, C. 2004. From "Traditional" Archaeology to Public Archaeology to Community Archaeology. In: SHACKEL, P. A; CHAMBERS, E. J. (eds.). Places in Mind: Public Archaeology as Applied Anthropology. London: Routledge.

MCGIMSEY, Ch. 1972. Public archaeology. Seminar Press, New York.

MERRIMAN, N. (ed.). 2004. Public Archaeology. London and New York: Routledge.

MERRYMAN, J. H. 2000. Thinking about the Elgin Marbles: Critical Essays on Cultural Property, Art and Law. London and Cambridge: Kluwer Law International.

MESKELL, L. 1998. Archaeology under Fire: nationalism, politics and heritage in the Eastern Mediterranean and Middle Eastern. London: Routledge.

2002. Negative Heritage and Past Mastering in Archaeology. Anthropological Quarterly, (75): 3, 557-574.

RIVOLTA, M. C; MONTENEGRO, M; ARGAÑARAZ, C. del V. 2010. In: FERREIRA, L. M; FERREIRA, M. L. M; ROTMAN, M. (orgs.). Multivocalidade nos Processos de Apropriação e Significação no Pucará de Tilcara. Patrimônio Cultural no Brasil e na Argentina: estudos de caso. São Paulo: CAPES/Annablume, pp. 173-192.

SARTRE, Jean-Paul. 1979. Prefácio. In: FANON, F. Os Condenados da Terra. Rio de Janeiro: Civilização Brasileira, pp. 3-21.

SCHOFIELD, J; JOHNSON, W. G. 2006. Archaeology, Heritage and the Recent and Contemporary Past. In: HICKS, D; BEAUDRY, M. C. (eds.). Historical Archaeology. Cambridge: Cambridge U. P., pp. 104-122.

SHACKEL, P. 2001. Public Memory and the Search for Power in American Historical Archaeology. American Anthropologist, (103): 3, 655-670.

SHEPHERD, N. 2009. “Cuando la Mano que Sostiene el Palustre es Negra...”. Prácticas Disciplinarias de Auto-Representación y el Asunto de la Mano de Obra "Nativa" en Arqueología. Arqueología Suramericana, (5): 1, 3-20.

SILBERMAN, H. 2002. Touring Ancient Times: The Present and Presented Past in Contemporary Peru. American Anthropologist, (104): 3, 881-902.

SILVA, F. A. Patrimônio Arqueológico em Terras Indígenas: Considerações sobre o Tema no Brasil. In: FERREIRA, L. M; FERREIRA, M. L. M; ROTMAN, M. (orgs.). Patrimônio Cultural no Brasil e na Argentina: estudos de caso. São Paulo: CAPES/Annablume, pp. 193218. 
SIMPSON, M. G. 2001. Making Representations: Museums in the Post-Colonial Era. London: Routledge.

SIMPSON, F; WILLIAMS, H. 2008. Evaluating Community Archaeology in the UK. Public Archaeology, (7): 2, 69-90.

SKINNER, Q. 1996. As Fundações do Pensamento Político Moderno. São Paulo: Companhia das Letras.

SMITH, C; WOBST, H. M. (eds.). 2005. Indigenous Archaeologies: Decolonizing Theory and Practice. London: Routledge.

TEGA, G. 2012. Arqueologia no Brasil e o Panorama Atual: os números de 11 anos de divulgação na Folha de São Paulo. Arqueologia Pública, (5): 14-27.

THOMAS, N. 1991. Colonialism's Culture: Anthropology, Travel, and Government. Princeton: Princeton U. P.

TRIGGER, B. G. 1984. Alternative Archaeologies: Nationalist, Colonialist, Imperialist. Man, (19): 355-370.

TULLY, G. 2007. Community Archaeology: General Methods and Standards of Practice. Public Archaeology, (6): 155-187.

TURNER, V. 2005. A Floresta dos Símbolos: Aspectos do Ritual Ndembu. Niterói: Editora da UFF.

WATSON, P. J. 2008. Processualism and After. In: BENTLEY, R. A; MASCHNER, H. D. G; CHIPPINDALE, C. (eds.). Handbook of Archaeological Theories. New York: Altarmira Press, pp. 29-37.

WICHERS, C. A. de Moraes. 2010. Museus e Antropofagia do Patrimônio Arqueológico: caminhos da prática brasileira. Lisboa: Programa de Pós-graduação em Museologia, Universidade Lusófona de Humanidades e Tecnologia (tese de doutorado).

ZANETTINI, P. E. 2009. Projetar o Futuro para a Arqueologia Brasileira: um desafio de todos. Revista Americana, (27): 71-87. 